\title{
COMMENTAIRE COMPOSÉ: \\ LEITURA EXISTENCIALISTA DE UM EXCERTO \\ DA PROSA DE FICÇÃO CLARICEANA
}

Hugo Lenes Menezes*

Liberdade épouco.

O que desejo ainda não tem nome.

Clarice Lispector

RESUMO: Escritora de costumes, dos altos e baixos existenciais de seres nada épicos num cotidiano indistinto, Clarice Lispector é uma aguda perscrutadora da psique ou alma humana. Então, no trabalho ora apresentado, resultante de sugestão de pesquisa à professora de Filosofia e de Letras Jeanne Marie Gagnebin de Bons, na Universidade Estadual de Campinas (UNICAMP), para a nossa monografia da disciplina Crítica I (1995), entre os métodos e técnicas da crítica literária, optamos pelo Commentaire Composé, método francês através do qual analisamos, do primeiro romance de Clarice Lispector, qual seja, Perto do coração selvagem (1943), um excerto, como exata ilustração do pensamento do filósofo existencialista Jean-Paul Sartre, especialmente no tocante à liberdade. Isso porque o citado romance narra a trajetória existencial de Joana, uma órfã de mãe que, desde tenra idade, manifesta forte individualidade em conflito com a família e a sociedade, por entender que, consciente de uma provável consequência repressora, ela pode tudo.

PALAVRAS-CHAVE: Liberdade; Clarice Lispector; Existencialismo; Jean-Paul Sartre.

\section{Considerações iniciais}

A liberdade constitui uma questão palpitante e firma-se no Ocidente, desde a Antiguidade Clássica, como uma constante no pensamento universal, sob várias perspectivas. Entre elas, destacamos a da corrente existencialista, que vem de Aristóteles, passa por Kierkegaard, Heidegger e Jaspers. Cresce gradualmente em importância, até vir a ser, depois do segundo conflito mundial, uma vertente filosófico-literária, cujo representante mais popular e na linha ateia é Jean-Paul Sartre, que desenvolve uma teoria da liberdade na sua conferência proferida em 1946, O existencialismo é um humanismo, transcrita na forma de tratado, gênero de investigação que se presta à linguagem estético-verbal ou:

[...] dela se utiliza para exprimir-se. [...] o texto literário funciona como instrumento do pensar filosófico: esse necessitado de um veículo para se comunicar, ou de um laboratório experimental, adota a Literatura movido pela identidade básica, resultante de o Existencialismo e a arte literária centrarem a sua atenção no desenvolvimento da existência. [...] A consequência é um romance e um teatro nos quais se põe em situação o drama do ser humano, cuja existência se desentola antes da essência, na fruição de uma liberdade tão plena que lhe dá a sensação de vagar no reino do gratuito. [...] Em vernáculo, o Existencialismo literário nota-se na obra de uma Clarice Lispector. (MOISÉS, 1982, p. 218)

\footnotetext{
* Doutor em Teoria e História Literária pela Universidade Estadual de Campinas (Unicamp).Professor do Instituto Federal do Piauí (Ifpi).
} 
A questão da liberdade, no que tange à linha filosófica enfocada, assenta-se no livrearbítrio, na capacidade que qualquer um de nós tem para decidir sobre o seu percurso vivencial, cujo significado preponderante é a intensidade revelada mediante a escolha e a correspondente responsabilidade, a qual se mostra bem ampla, ao recair tanto sobre o indivíduo, quanto sobre a humanidade. Apenas o homem possui competência existencial de se autoconstruir, pois tudo sucede após a sua existência. De onde ser necessário o reconhecimento do sujeito que quebra as amarras com a sociedade e coloca-se como fundador de si e do mundo.

Cada um faz as suas opções, que geram mudanças coletivas. Por conseguinte, verificamos a negação do determinismo em Sartre, para quem nada pode ser esclarecido com base numa natureza humana dada e definitiva. Até porque, ainda segundo o mesmo pensador, a pessoa é a senhora do seu destino, está condenada "a ser livre e toda a sua existência decorre dessa condição" (SARTRE, 1987, p. 11), a de que o homem em si é liberdade. E o fato de nada poder nos salvar da tarefa de decidir suscita o desamparo, o qual "implica que somos nós que escolhemos o nosso ser" (SARTRE, 1987, p. 12).

Ainda no entender do autor de Os caminhos da liberdade (1945-1949), para sermos completamente livres, a ideia de Deus deve ser eliminada e somente cabe à pessoa, que para Sartre não é projetada por um criador, estabelecer valores, por meio do que pode guiar os seus mais diversos atos, questionar a sua própria existência, cuja possibilidade única é a liberdade, sem procurar desculpas no senso comum ou na religião, quando, por exemplo, atribui possíveis malogros à vontade de Deus ou ao destino. Apenas ao se lançar “[...] em direção às suas opções é que o homem desperta para aquilo que o rodeia e transforma a circunstância em matéria do seu destino" (LIBANORI, 2010, p.118), sem mascarar, em face da decisão, a angústia existencial, que é fruto da liberdade e da responsabilidade, diante de outras possibilidades não escolhidas, angústia essa que pode se exprimir fisicamente pela náusea, a qual, aliás, dá título a um romance sartriano de 1938.

Para o sujeito humano, a recorrência a desculpas parece ser mais cômoda do que contar unicamente consigo, o que o leva a ficar sem esperança e de má-fé. Essa última é a negação da liberdade, de toda a realização do existente, e oculta uma ausência de engajamento, o qual é a única salvação, conforme esse Existencialismo de ação, não contemplativo. Aqui, ser livre é comprometer-se. O indivíduo de má-fé foge da liberdade, da responsabilidade pessoal e social, o que equivale a negar o pressuposto fundamental da nossa trajetória no mundo, o de que a existência precede a essência. E, para tal indivíduo, resta só “o vazio do nada, 
identificado com a morte soberana e afinal vitoriosa" (MOISÉS, 1982, p. 218). E como não nos lembrarmos da denominação da obra-prima de Sartre: O ser e o nada (1934)?

Conforme referimos, para o Existencialismo, a arte verbal funciona como um instrumento de expressão. Assim, no artigo ora apresentado, resultante de sugestão de pesquisa à professora de Filosofia e de Letras Jeanne Marie Gagnebin de Bons, na Universidade Estadual de Campinas (UNICAMP), para a nossa monografia da disciplina Crítica I em 1995, durante o nosso Mestrado, entre os métodos e técnicas da crítica literária, optamos pelo Commentaire Composé, método francês através do qual analisamos um excerto do primeiro romance clariciano, Perto do coração selvagem (1943), excerto esse que é uma perfeita exemplificação do pensamento do intelectual parisiense, especialmente no tocante à liberdade. ${ }^{1}$

\section{Clarice Lispector escritora}

Clarice Lispector, nascida na Ucrânia, corporiza, no gênero feminino, uma das mais elevadas sensibilidades da literatura brasileira, da qual ela é uma das matrizes, a exemplo de Machado de Assis, Oswald de Andrade, Mário de Andrade e Guimarães Rosa. Por meio da sua produção, na qual se mostra uma profunda observadora dos caracteres, ela vai muito além do seu propalado intimismo. Com esse e numa postura reducionista, a autora de Perto do coração selvagem costuma ser rotulada, por utilizar a introspecção das personagens, o monólogo interior, o fluxo da consciência, o discurso indireto livre e a análise psicológica.

De nossa parte, sem querer classificar a literata em causa, essa é encarada como uma ficcionista de estruturas inovadoras, a partir da cena mundial e do contexto histórico nacional da década de 1960 e os seus anos pós-1964, marcados pela censura do sistema repressivo implantado no País, depois de a escritora brasileira estrear em 1943, numa época de igual governo arbitrário, e posteriormente vir a lançar, entre outras produções, Uma aprendiragem on O livro dos prazeres (1969). Desse romance, que começa com uma vírgula, alguns fragmentos são primeiro estampados, com variações, na forma de crônicas para o Jornal do Brasil. E a sua inusitada introdução, segundo Benedito Nunes (2020), indica que o relato deve ser lido como uma continuação de obras pregressas: Perto do coração selvagem, O lustre (1946), Laços de família (1960), A maçã no escuro (1961), A legião estrangeira (1964) e, em especial, A paixão segundo G.H. (1964), que, por sua vez, termina com dois pontos.

\footnotetext{
${ }^{1} \mathrm{O}$ aludido método francês, denominado Commentaire Composé, em linhas gerais, consiste no recorte de uma passagem representativa de uma obra literária para a realização de uma análise sintética.
} 
Particularmente, a short history é cultivada por Clarice Lispector com o talento dos estadunidenses John Cheever e John Updike; bem assim da neozelandesa Katherine Mansfield, que a nossa escritora admira e a quem é comparada, como também ela é comparada à britânica Virginia Woolf, ao irlandês James Joyce, ao italiano Italo Svevo e, em língua alemã, ao austríaco Robert Musil, todos eles prosadores de costumes, dos altos e baixos existenciais de seres humanos nada épicos num cotidiano indistinto. E parte da novelística da literata brasileira é uma ampliação temático-formal dos seus contos, naquela já considerada a mais importante coletânea pós-machadiana de narrativas curtas, que raiam pela perfeição, qual seja, Laços de família, precisamente uma ampliação dos "conflitos interiores insolúveis das protagonistas" (NUNES, 1989, p. 28) em subsequentes personagens-mulheres, como a de Apaixão segundo G.H (1964), originalíssimo romance.

Essa forma, no caso, a artista literária desenvolve por meio de capítulos/fragmentos em leixa-pren e, segundo a estudiosa Maria de Fatima do Nascimento, num tema-tabu, que fica antes apenas na esfera do desejo da personagem Natividade, figura do romance machadiano Esaú e Jacó (1904). Aludimos ao abortamento induzido na obra-prima A paixão segundo G.H., que, "pela sutileza da sua estrutura fragmentária, o encobre no enredo" (NASCIMENTO, 2012, p. 305). Outro tema-tabu em Clarice Lispector é o incesto, enfocado anteriormente nos lusos romances queirosianos $A$ tragédia da Rua das Flores (1877-1878) e Os Maias (1888); no igualmente romance Absalão, Absalão! (1936), do norte-americano William Faulkner, e insinuado num subestimado romance clariciano, traduzido para o inglês só em 2018 nos Estados Unidos da América. Falamos de O lustre (1946), em que outra estudiosa, Nádia Gotlib aponta a existência do incesto, ao desenvolver o seu livro Clarice: uma história que se conta (1995). De acordo com reflexões suas:

Tal como Joana, de Perto do coração selvagem, Virgínia, a personagem principal do romance $\mathrm{O}$ lustre, tem a sua história narrada desde a sua infância e também aparece sob o signo do Mal. Agora, a partir de um relacionamento de caráter incestuoso com o irmão, Daniel, com quem mantém um pacto: reuniões secretas em que experimentam certas verdades, na condição de iniciados especiais. (GOTLIB, 1995, p. 255)

Não obstante o comentário supracitado, no artigo intitulado "O lustre, de Clarice Lispector: indícios de incesto", integrante da produção Dialéticas amarônicas da literatura (2019), organizada por Juciane Cavalheiro e Gerson Albuquerque, a pesquisadora Maria de Fatima do Nascimento ressalva que:

Nádia Gotlib chega a admitir, de passagem, a presença de um envolvimento incestuoso entre os dois irmãos para centrar-se nas experiências de Virgínia, sem 
abordar os discursos do narrador que poderiam explicitar semelhante fato na narrativa. (NASCIMENTO, 2009, p. 189)

Ademais, na comprovação de que a romancista de $A$ maçã no escuro vai além do intimismo, em tal obra pouco analisada, alguns sinais (a exemplo da terra seca e a preocupação da protagonista Vitória com a estiagem) evocam o espaço geográfico do Nordeste brasileiro e demonstram que a nossa ficcionista, transferida ainda criança, como exilada, para Recife Pernambuco, precedentemente ao livro $A$ bora da estrela (1977), faz uso da função políticosocial da arte da palavra, ao situar o enredo numa região física e humanamente marginalizada, porém focalizada desde o nosso período colonial. Ainda em $A$ maçã no escuro, ao lado da questão cultural de gênero, recorrente em Clarice Lispector e nela referente à condição social da mulher, deparamos com a presença da questão étnica numa inominada serviçal negra, a qual o texto nos sugere ter sido vítima de um estupro por parte de Martim, a personagem central masculina (informação verbal) ${ }^{2}$. Nesse contexto e na estreia clariciana, a criadora de Perto do coração selvagem já dialoga com a Filosofia Existencialista, sobretudo a do engajado Jean-Paul Sartre, sob a premissa de que a vida é feita de escolhas.

Aliás, à luz do questionamento existencialista da liberdade, o milenar mito universal da demonização da mulher ressurge em Perto do coração selvagem. O demônio e a mulher, para além da chamada tentação, sugerem semelhanças. Tidos como entes misteriosos e perigosos, ambos costumam ser associados, na psique humana, ao seu lado lucífugo, alusão ao rebelde e altivo Lúcifer. Tal instância mental é propensa a ataques ou investidas impetuosas e a transgressões, como ilustra o mito bíblico do criacionismo. Ali, Eva, dita a primeira mulher, colocada no Éden, jardim de delícias, transgride a ordem preestabelecida, ao provar do fruto proibido, oferecido pelo demônio, zoomorfizado em serpente, e ao oferecê-lo ao marido Adão. É cometido então o considerado primeiro pecado, alegado como a causa da nossa morte. Imagem antitético-ideológica de Maria, serva do Deus judaico-cristão, Eva, sedutora e libertária, é vista como revoltosa, demonizada, aquela que "engana e desgraça” o homem, na criatura de Adão. Inclusive, o filme a Paixão de Cristo (2004), de Mel Gibson, e a telenovela bíblica Jesus (2018), de Paula Richard, trazem mulheres no papel do demônio. Segundo um adágio popular: "A mulher engana até o diabo" e chega a simbolizar o demônio na história

\footnotetext{
2 Interpretações obtidas mediante a fala acadêmica intitulada "Estudos de Benedito Nunes sobre a obra de Clarice Lispector", uma participação da professora de Literatura Brasileira Maria de Fatima do Nascimento na mesa-redonda 1 de um evento por ela organizado, qual seja, Sem Clarice: um colóquio pelos 40 anos de morte, na sua Instituição de Ensino Superior, a Universidade Federal do Pará (UFPA), entre 6 e 7 de dezembro de 2017. Programação do evento em: https://semclariceumcoloquio40.wordpress.com/2017/10/09/programacaosem-clarice-um-coloquio-pelos-40-anos-de-morte/
} 
da "caça às bruxas", mesmo sem a mulher ser de fato uma delas, mas apenas uma pessoa de estilo de vida fora do comum. Pertinentemente, Daniel Gruber observa que:

\begin{abstract}
Como demonstrou a historiadora Silvia Federici e dezenas de outras estudiosas, a febre da caça às bruxas não foi aleatória e, sim, uma política sexual que visava reprimir e controlar o corpo e o comportamento feminino. Essa prática [...] perdurou na legislação até as vésperas da era contemporânea. Em Portugal e no Brasil não houve uma caça às bruxas sistemática como no norte da Europa. Mesmo assim, como se pode averiguar nos registros da Inquisição, algumas centenas de mulheres foram encarceradas, açoitadas, torturadas, mandadas para longe das suas famílias e, em alguns casos, queimadas em autos de fé. [...] fica clara a mentalidade misógina da caça às bruxas, retratando a mulher como naturalmente maliciosa e propícia às tentações do demônio. Essa mentalidade formou boa parte da cultura brasileira. Depois, sabemos onde tudo isso termina: o aumento assustador dos índices de feminicídio no País mostra que a caça às bruxas continua viva, forte e violenta. Continua sendo uma política de estado. (GRUBER, 2020, s.n.)
\end{abstract}

Tal assunto é glosado, como alegoria política, no romance As bruxas de Eastwick (1984), do estadunidense John Updike. Em vernáculo, é exemplar o conto de bruxarias "A dama pé de cabra" (1843), do português Alexandre Herculano, que, em tal narrativa, reelabora a demonização da mulher. Um século depois, a grande dama da literatura brasileira aborda semelhante tema em Perto do coração selvagem. Por fim, a retromencionada ampliação de contos para romances em Clarice Lispector, leitora de Machado de Assis, também ocorre no autor carioca. A título de exemplificação, podemos referir que o núcleo temático da história curta “Trio em lá menor”, do livro Várias histórias (1896), é retomado no romance Esaú e Jacó. Bruxa, na instância figurativa, para Vilma Arêas, autora de Clarice Lispector com a ponta dos dedos (2005), publicação laureada pela Associação Paulista de Críticos de Arte (APCA), a nossa literata, curiosamente participante do I Congresso de Bruxaria em Bogotá (1975), e o Bruxo do Cosme Velho são dois perscrutadores da psique ou alma humana, atentos também à nossa conjuntura social.

\title{
Leitura existencialista de um excerto clariciano
}

O romance clariciano Perto do coração selvagem centra-se na trajetória existencial de Joana, uma órfã de mãe que habita com o genitor e manifesta forte individualidade desde tenra idade. Nessa fase, ela faz indagações capciosas a adultos, como o seu pai, na primeira instituição em que convive, a família, e depois a professores, na segunda instituição, a escola. Após o falecimento paterno, a garota vai residir juntamente a um casal de tios. Com tais parentes, principalmente a tia, que não tolera aquilo que julga o traço de amoralidade da sobrinha, essa se acha uma intrusa. O conflito familiar atinge o ápice depois do flagrante episódio de um furtivo roubo, cometido por Joana, como teste para si e como provocação, 
apenas por querer, por acreditar e entender que, consciente de uma provável consequência repressora da sociedade e, igualmente ao rebelde e altivo Lúcifer, ela pode tudo.

Em seguida, chega à consequência de tal ato. No citado casal, o acontecido desencadeia uma conversa aterrorizada, durante a qual a esposa declara desobrigar-se da sobrinha. Finalmente, os tios concluem que a disciplina rígida de um colégio interno religioso pode domar a menina e até exorcizar o demônio de dentro dela, que é tida como praticante de um dos mais ofensivos pecados, na concepção da tia, a qual, chocada com a reação sem culpa da garota, classifica-a como um signo do mal, uma víbora, "um bicho estranho [...], sem amigos, sem Deus [...]; um pequeno demônio" (LISPECTOR, 1980, p. 45). Contudo, no internato só aumentam, ainda mais, as divergências entre Joana e o seu entorno, pela vida adiante.

Cabe-nos, então, ponderar que os seres ficcionais de Clarice Lispector habitualmente se desvencilham do que, de forma genérica, tratamos aqui como práticas sociais, ou seja, um complexo de modos usuais de condutas e de compreensão da existência. Nesse sentido, Benedito Nunes, uma referência nos estudos da nossa autora, assinala que, nas narrativas dela, particularmente nos seus romances, "acentua-se, com a sondagem interior descendo ao nível microscópico onde a causalidade é minúscula e minuciosa, um horizonte reflexivo e até especulativo de sondagem existencial" (NUNES, 1973, p. 20). A produção Perto do coração selvagem é um cenário da sondagem aludida pela voz nuniana, como bem demonstra, na primeira parte da obra, um incidente do sétimo capítulo, intitulado "O banho", do qual transcrevemos e comentamos um excerto. Vejamos:

No momento em que a tia foi pagar a compra, Joana tirou o livro e meteu-o cuidadosamente entre os outros, em baixo do braço. A tia empalideceu. Na rua a mulher buscou as palavras com cuidado:

- Joana... Joana, eu vi...

Joana lançou-lhe um olhar rápido. Continuou silenciosa.

— Mas você não diz nada? — não se conteve a tia, a voz chorosa. - Meu Deus, mas o que vai ser de você?

— Não se assuste, tia.

— Mas uma menina ainda... Você sabe o que fez?

- Sei...

- Sabe... sabe a palavra...?

— Eu roubei o livro, não é isso?

- Mas, Deus me valha! Eu já nem sei o que faço, pois ela ainda confessa!

- A senhora me obrigou a confessar.

- Você acha que se pode... que se pode roubar?

- Bem... talvez não.

- Por que então...?

- Eu posso.

— Você?! — gritou a tia.

- Sim, roubei porque quis. Só roubarei quando quiser. Não faz mal nenhum.

- Deus me ajude, quando faz mal, Joana?

— Quando a gente rouba e tem medo. Eu não estou contente nem triste.

A mulher olhou-a desamparada: - Minha filha, você é quase uma mocinha, pouco falta para ser gente... Daqui a dias terá que abaixar o vestido... Eu lhe imploro: prometa que não faz mais isso, prometa (...). 
Joana olhou-a com curiosidade: - Mas se eu estou dizendo que posso tudo, que... Eram inúteis as explicações (LISPECTOR, 1980, p. 44-52).

O curioso diálogo acima reproduzido é um grande indicativo da lógica própria da heroína clariceana em tela, especialmente acerca das noções de certo e errado, bem assim da onipotência da protagonista diante dos valores tradicionais, com vistas a ser o sujeito da sua história. Em meio à rara consciência crítica de existir, tudo isso ocorre como parte do processo de descobrir-se, encontrar uma razão de ser, sem receio de romper com o ensinado e de instaurar nova ética e moral, única e exclusivamente baseada na confirmação responsável do direito à existência pessoal. A respeito disso, Sartre se pronuncia da seguinte maneira:

[...] o que se poderia chamar de moralidade cotidiana exclui a angústia ética. Há angústia ética quando me considero na minha relação original com os valores. [...] Daí que a minha liberdade é o único fundamento dos valores e nada, absolutamente nada, justifica a minha adoção dessas ou daquelas escalas de valores. ( $S A R$ TRE, 1987, p. 12)

Em outras palavras, no contexto em pauta, viver é o valor dos valores e não pode se submeter a nenhuma outra moralidade. Em Perto do coração selvagem, a personagem central concebe que deve "viver largamente", como vemos também na estética de Fernando Pessoa/Álvaro de Campos, que almeja "sentir tudo de todas as maneiras, viver tudo de todos os lados" (PESSOA, 1999, p. 92). Em tal esfera, o roubo furtivo de um livro (grifo nosso) leva Joana a exprimir as suas ideias morais, a pôr em questão os valores do mundo adulto e, mais ainda, a transgredi-los, o que traz à tona:

\begin{abstract}
[...] todo o horror da tia à completa displicência de Joana em relação ao socialmente condenável e criminoso ato de roubar. É interessante ainda a relação intrínseca estabelecida entre o poder creditado à palavra roubar, de conotação negativa [...], e as emoções associadas a tal palavra - emoções [...] que conferem ao ato um julgamento de valor. Como "não tem medo" ao furtar o objeto; como não se sente "contente nem triste" durante a ação (aqui um acontecimento livre de arrependimentos, culpas ou vitórias), a menina considera que aquilo "não faz mal nenhum" e o fará de novo só "quando quiser", e trata seu próprio desejo como único elemento de motivação ou proibição do crime. (FREITAS, 2017, p. 92)
\end{abstract}

Nesse contexto, Sartre (1987, p. 12) reitera ser a liberdade a condição de seres conscientes e responsáveis pelas suas ações e consequências, ao tempo em que julga que a consciência pode ser descrita como liberdade. Então, para melhor entendimento de como a consciência/liberdade é movida pela intencionalidade, cumpre-nos comentar os conceitos daquilo que o pensador francês chama em-si e para-si. O em-si é tudo que existe, com exceção da representação subjetiva da consciência humana, designada para-si, âmbito necessariamente livre da existência, ou o exercício da prerrogativa de liberdade do homem. Enquanto o emsi é o domínio que é ultrapassado pela liberdade. As ameaças que o para-si sofre devem se 
transformar em estímulos, a fim de que o ser humano realize o seu projeto de existência, com o qual deve achar-se comprometido.

Constatamos, pois, que Joana comete um ato em-si (um roubo furtivo), plenamente natural para ela, que o encara enquanto prática da sua liberdade. A tia, porém, o considera um ato para além de si, já que a garota transgride uma norma estabelecida antes da sua existência (não roubar), o que para Joana equivale a uma manifestação do ser livre. Esse, para Sartre, somente pode ser aceito como absoluto ou inexistente. Além disso, porquanto a liberdade aqui é concretizada numa ação voluntária, no intuito de mudar a configuração da sociedade, a pessoa não pode se deixar dominar pelo conformismo. E o mundo não tem que ser visto como concluído, de uma posição contemplativa, mas é para ser:

[...] operado e, portanto, só se manifesta, no seu relevo próprio, a quem vai a ele numa atitude prática. Nada há que venha de fora ou de dentro a que o homem deva seguir ou obedecer senão por volição pessoal. O homem não é um ser feito, mas um ser que se faz, e a sua única predeterminação é a de se fazer até os seus últimos detalhes. [...] Ele é o próprio instaurador do sentido do mundo. [...] Não somos humanos, pois, como se é pedra, céu ou árvore. Mas somos convocados à humanidade, ou seja, tornamo-nos humanos. [...] O homem é uma proposição de um projeto de vida, um ser que supera o mundo na sua objetividade. $\mathrm{O}$ seu poder criador é uma vitória sobre a vida concreta. (LIBANORI, 2010, p. 124)

\section{Considerações finais}

No Commentaire Composé apresentado no presente artigo, analisamos um excerto do clariciano Perto do coração selvagem, perfeita ilustração literária da filosofia sartriana no tocante à liberdade humana. Verificamos que os atos decisionais da nossa protagonista, cuja singularidade é ser amoralmente ela mesma, correspondem àqueles postulados pelo intelectual parisiense em $O$ existencialismo é um humanismo e oferecemos um exemplo: Joana serenamente declara ter praticado um roubo furtivo e que pode vir a fazê-lo outra vez, caso sinta vontade, uma vez que é livre para realizar as suas escolhas e se sente disposta a arcar com as implicações de tudo o que faz. Essa e outras atitudes, em virtude das quais a personagem é demonizada no seu círculo, tornam Perto do coração selvagem um apelo a todos que, plenamente identificados com a liberdade, não temem subverter as convenções sociais.

\section{COMMENTAIRE COMPOSÉ: LECTURE EXISTENTIALISTE D'UN EXTRAIT DE LA PROSE DE FICTION CLARICIENNE}

RÉSUMÉ : Clarice Lispector, écrivain des coutumes, des questions existentielles des êtres ordinaires dans un quotidien terne, est une chercheuse profonde de la psyché ou de l'âme. Puis, dans l'article que nous présentons, résultant d'une suggestion de recherche à l'enseignante de philosophie et lettres Jeanne Marie Gagnebin de Bons, à l'Université de Campinas (UNICAMP), pour notre monographie de la discipline Critique I (1995) entre 
les méthodes et techniques de critique littéraire, nous choisissons le Commentaire Composé, méthode français à travers lequel nous analysons, de le premier roman de Clarice Lispector, c'est-à-dire, Près du coeur sauvage (1943), um extrait, comme illustration exacte de la pensée du philosophe existentialiste Jean-Paul Sartre, notamment sur la question de la liberté. C'est parce que le Roman cite raconte la trajectoire existentielle de Joana, une orpheline qui, dês son jeune âge, exprime sa forte individualité em conflit avec la famille et la société, même consciente des conséquences.

MOTS CLÉS : Liberté; Clarice Lispector; Existentialisme; Jean-Paul Sartre.

\section{REFERÊNCIAS}

ARÊAS, Vilma. Clarice Lispector com a ponta dos dedos. São Paulo: Companhia das Letras, 2005.

FREITAS, Clara Júlio. Afetividade em cena: uma leitura de Clarice Lispector. 2017. Dissertação (Mestrado em Literatura Brasileira) - Faculdade de Letras, Universidade Federal de Minas Gerais, Belo Horizonte, Minas Gerais, 2017.

GOTLIB, Nádia Batella. Clarice: uma vida que se conta. São Paulo: Edusp, 2009.

GRUBER, Daniel. Feiticeira: mulher que faz e dá feitiço. Disponível em: https://www.facebook.com/daniel.gruber.338. Acesso em: 24 jan. 2020.

LIBANORI, Evely Vânia. Clarice Lispector e Vergilio Ferreira: a existência problematizada. Acta Scientiarm. Language and Culture, Maringá: UEM, v. 32, n.1, p. 117-124, jan./jun. 2010.

LISPECTOR, Clarice. Perto do coração selvagem. Rio de Janeiro: Nova Fronteira, 1980.

NASCIMENTO, Maria de Fatima do. O lustre de Clarice Lispector: indícios de incesto. In: CAVALHEIRO, Juciane; ALBUQUERQUE, Gerson (Orgs.). Dialéticas amazônicas da literatura. Manaus: Editora UEA, 2019.

Benedito Nunes e a moderna crítica literária brasileira (1946-1969) - $1^{\circ}$ Vol. 2012. Tese

(Doutorado em Teoria e História Literária) - Instituto de Estudos da Linguagem, Universidade Estadual de Campinas, Campinas, São Paulo, 2012.

MOISÉS, Massaud. Existencialismo. In: Dicionário de termos literários. São Paulo: Cultrix, 1982.

NUNES, Benedito. Leitura de Clarice Lispector. Petrópolis: Vozes, 1973.

O drama da linguagem: uma leitura de Clarice Lispector. São Paulo: Ática, 1989.

O dorso do tigre. São Paulo: Editora 34, 2009.

Uma aprendizagem ou o livro dos prazeres. Disponível em: https://pt.wikipe-

dia.org/wiki/Uma_Aprendizagem_ou_O_Livro_dos_Prazeres. Acesso em: 24 jan. 2020.

PESSOA, Fernando. Passagem das horas. In: Poemas de Álvaro de Campos (Fixação de texto, introdução e notas de Cleonice Berardinelli). Rio de Janeiro: Nova Fronteira, 1999.

SARTRE, Jean-Paul. O existencialismo é um humanismo. In: Os pensadores: Sartre. São Paulo: Nova Cultural, 1987. 